Article

\title{
Preparation and Characterization of Novel Plaster with Improved Thermal Energy Storage Performance
}

\author{
Jan Fořt ${ }^{1,2, * \mathbb{D}}$, Radimír Novotný ${ }^{1}$, Anton Trník ${ }^{2,3}$ and Robert Černý ${ }^{2}$ a \\ 1 Institute of Technology and Business in České Budějovice, Okružní 517/10, \\ 37001 České Budějovice, Czech Republic \\ 2 Department of Materials Engineering and Chemistry, Faculty of Civil Engineering, Czech Technical \\ University in Prague, Thákurova 7, 16629 Prague 6, Czech Republic \\ 3 Department of Physics, Faculty of Natural Sciences, Constantine the Philosopher University in Nitra, \\ A. Hlinku 1, 94974 Nitra, Slovakia \\ * Correspondence: jan.fort@fsv.cvut.cz
}

Received: 25 July 2019; Accepted: 26 August 2019; Published: 28 August 2019

check for updates

\begin{abstract}
Thermal energy storage systems based on latent heat utilization represent a promising way to achieve building sustainability and energy efficiency. The application of phase change materials (PCMs) can substantially improve the thermal performance of building envelopes, decrease the energy consumption, and support the thermal comfort maintenance, especially during peak periods. On this account, the newly formed form-stable PCM (FSPCM) based on diatomite impregnated by dodecanol is used as an admixture for design of interior plasters with enhanced thermal storage capability. In this study, the effect of FSPCM admixture on functional properties of plasters enriched by 8,16 and $24 \mathrm{wt} . \%$ is determined. On this account, the assessment of physical, thermal, hygric, and mechanical properties is done in order to correlate obtained results with applied FSPCM dosages. Achieved results reveal only a minor influence of applied FSPCM admixture on material properties when compared to negative impacts of commercially produced PCMs. The differential scanning calorimetry discloses variations of the phase change temperature, which ranging from $20.75^{\circ} \mathrm{C}$ to $21.68^{\circ} \mathrm{C}$ and the effective heat capacity increased up to $15.38 \mathrm{~J} / \mathrm{g}$ accordingly to the applied FSPCM dosages.
\end{abstract}

Keywords: phase change temperature; plaster; thermal energy storage; mechanical properties; thermal properties

\section{Introduction}

Nowadays, the rising energy consumption related to the building sector is a source of concern associated with the energy inefficiency and excessive production of greenhouse gases (GHG). Namely, the buildings sector consumes about $40 \%$ of annually produced primary energy in the European Union and is responsible for the production of almost $25 \%$ of greenhouse gases (GHG) [1]. Another important issue is linked with the rise of fuel prices and abandonment of conventional energy sources, including the combustion of fossil fuels which are viewed as one of the major sources of excessive emissions [2]. However, despite several developed mitigation strategies aimed at improvements of the energy performance, the achieved results and observations cannot be considered satisfactory in terms of sustainable development goals.

Presently, the utilization of traditional insulation materials such as polystyrene, mineral wool or polyurethane foam have reached the maximal insulation potential. Thus the thermal stability of buildings can be upgraded only by advanced energy improvement provisions or combination of several strategies [3]. The recent development of innovative insulation materials such as vacuum insulation panels, gas-filled panels or aerogels represents a very efficient method for the energy performance of 
building envelopes, however despite the superior thermal resistance of mentioned materials, ambitious GHG mitigation targets require the employment of additional methods [3-5]. As one of the most critical parameters can be seen in a low thermal inertia of current insulation materials and consequent limited thermal stability of building envelopes during peak periods [6]. Moreover, considering the recent knowledge related to the energy efficiency of buildings and oncoming climate change [7], requirements on interior air quality maintenance are going to be more important in the near future, when the peak temperatures will be probably increased.

Advanced systems of the thermal energy storage have been extensively studied to meet energy efficiency criteria with increased demands on the maintenance of indoor thermal comfort of modern residential and office buildings [8]. Thermal energy storage systems have been found to be a beneficial step towards balancing the energy availability and energy demand period for heating and cooling [9]. Specifically, the passive cooling/heating technology based on the utilization of latent heat could substantially contribute to the preservation of ambient thermal comfort and consequently reduce the costs associated with energy consumption. The high potential of PCMs lays especially in the effectivity during daily temperature variations and subsequent mitigation of indoor temperature swings. Considering the application of PCMs in the construction sector, several approaches contemplating PCM incorporation into building elements can be identified.

However, several limitations for passive heating/cooling PCM-based systems have been revealed [10]. Since the passive systems completely depend on fluctuations of outdoor temperature, identification of ideal PCM having a suitable temperature operating range is required to drop/overcome the solidification/melting point. Otherwise, inappropriately selected PCMs cannot serve as cooling/heating support and the efficiency of the system is limited. This problem can be solved by the utilization of addition HVAC devices, nevertheless, their use lessens the gained benefits. As is evident, a proper understanding and determination of PCMs properties poses an essential knowledge base for thermal energy system application and promotion of their great potential [11].

The temperature moderation capability of PCMs has attracted the attention of several researchers intending to develop concrete with improved thermal storage properties [12,13]. However, according to the restriction related to the negative effect of incorporated PCMs on material properties, a major barrier can be viewed in PCMs compatibility with cementitious materials, which limits broader PCM applications [14]. A subsequent optimization of the applied dosages of PCMs in order to increase the thermal storage capacity improved the efficiency up to $35 \%$, which resulted in decreased overheating rate as well as in increased economic viability [15].

Another substantial obstacle for a broader application of thermal energy storage is the negative effect of commercially produced polymer-based PCMs on the functional properties of modified materials. Despite the beneficial effect of PCMs on preservation of ambient climate with reduced energy consumption, the PCMs incorporation into cementitious materials is accompanied by many issues such as abrasion of PCM shells, clumping or segregation of PCM particles, and leakage of PCM media [12,16]. Especially, notable leakage together with a poor compatibility with cementitious materials represent major barriers for PCM utilization. Minor improvements in the field of microencapsulated PCM applications were presented by Zhang et al. [17] and Sari et al. [18], however attempts aimed at fabrication of form-stable PCMs can be viewed as major breakthrough. The impregnation method based on the absorption of paraffin/salt by a suitable bearer with a highly porous structure has been reported as a promising solution overcoming the problems described above. For example, He et al. [19] have impregnated perlite with a combination of eutectic PCMs for application in cement mortars. These efforts resulted in the improvement of the thermal storage properties while the mechanical strength of fabricated PCMs was reduced only slightly and could meet the technical requirements for building mortars. It was found that the thermal and mechanical properties of mortars with PCMs are highly dependent on the porosity of the mortars [20]. In other words, the physical and chemical compatibility between particular materials represents a crucial factor for the effective design of PCM mortars [21]. 
Taking into account the abovementioned points, the development and experimental analysis of newly developed form-stable PCM (FSPCM) incorporated into plaster mixture were carried out. In this paper the following aspects were considered: the suitability of the developed FSPCM for incorporation into cement-lime plaster; the influence of the applied FSPCM admixture on the material properties of prepared plasters, and sufficient thermal energy storage capacity. Material functional performance is determined by the mean basic physical, mechanical, thermal, and hygric properties. Particular importance is given to the improvement and long-term stability of the thermal storage properties. The developed plasters can be easily applied as an additional interior layer to improve the thermal performance of light-weighted building envelopes with poor thermal inertia.

\section{Materials and Methods}

\subsection{Studied Materials}

The FSPCM was fabricated on the basis of a vacuum saturation principle using highly porous diatomite powder (LB Minerals, Horní Bříza, Czech Republic) together with $n$-dodecanol (Sigma-Aldrich, Taufkirchen, Germany) as a PCM medium. According to material characteristics provided by the producer; the phase change temperature is about $22{ }^{\circ} \mathrm{C}$ and the latent heat about $170 \mathrm{~J} / \mathrm{g}$. Dodecanol was mixed with diatomite particles in the selected ratio (about 0.85/1 according to pozzolanic test results) and placed in a VakuCell vacuum oven (BMT Medical Technology, Brno, Czech Republic. Both materials were subsequently heated, thus melted dodecanol impregnated the porous structure of diatomite particles. The obtained mixture was milled to crush clumped particles and obtain a powdered material. The whole procedure was repeated to ensure the uniform distribution of the dodecanol in the diatomite particles. After three cycles of vacuum saturation, the prepared FSCPM did not exhibit any leakage of liquid dodecanol during heating cycles thanks to the capillary and surface tension forces [22]. The utilization of diatomite as PCM bearer preserved the pozzolanic properties up to $0.85 / 1$ dodecanol diatomite ratio, based on the results of a Frattini test specified by the European standard ČSN EN 196-5 [23]. Such results predetermined the suitability for application in cementitious composites. The phase change temperature of the developed FSPCM was $23.15^{\circ} \mathrm{C}$ during heating and $21.13{ }^{\circ} \mathrm{C}$ during cooling. The phase change enthalpy reached $71.36 \mathrm{~J} / \mathrm{g}$ during cooling and $73.1 \mathrm{~J} / \mathrm{g}$ during the heating cycle [24].

The particle size distribution (PSD) of pure diatomite, reference cement-lime plaster, and the newly developed FSPCM was measured on an Analysette 22 Micro Tec plus device (Fritsch, Northamptonshire, United Kingdom, Figure 1) working on a laser diffraction principle. The measuring range of the applied apparatus covers particle sizes from $0.08 \mu \mathrm{m}$ up to $2000 \mu \mathrm{m}$. A green laser is used for the small particle range, whereas an infrared laser is utilized for the measurement of larger particles. The repeatability of the device according to ISO 13320 [25] is at $d_{50} \leq 1 \%$.

Designed plasters were prepared with a commercially available dry plaster mixture (Manu 1, Baumit, Dětmarovice Czech Republic) composed of hydrated lime, cement, sand with a maximal grain size about $1 \mathrm{~mm}$ and additives. Selected dry plaster mixture was modified by FSPCM admixture using weight dosages of about 8,16 and $24 \mathrm{wt} . \%$. Due to a different surface area and particle size of FSPCM compared to dry plaster mixture, the water dosages needed to be adjusted to maintain the same workability of prepared mixtures. Here, the workability was verified using the flow table test having the spread diameter was approx. $180 \mathrm{~mm}$ in both perpendicular directions. The composition of the studied materials is given in Table 1.

Cast samples were stored for 28 days in a highly humid environment. After curing, all samples were dried at $60^{\circ} \mathrm{C}$ for $48 \mathrm{~h}$ until constant mass and subjected to further experimental procedures. 


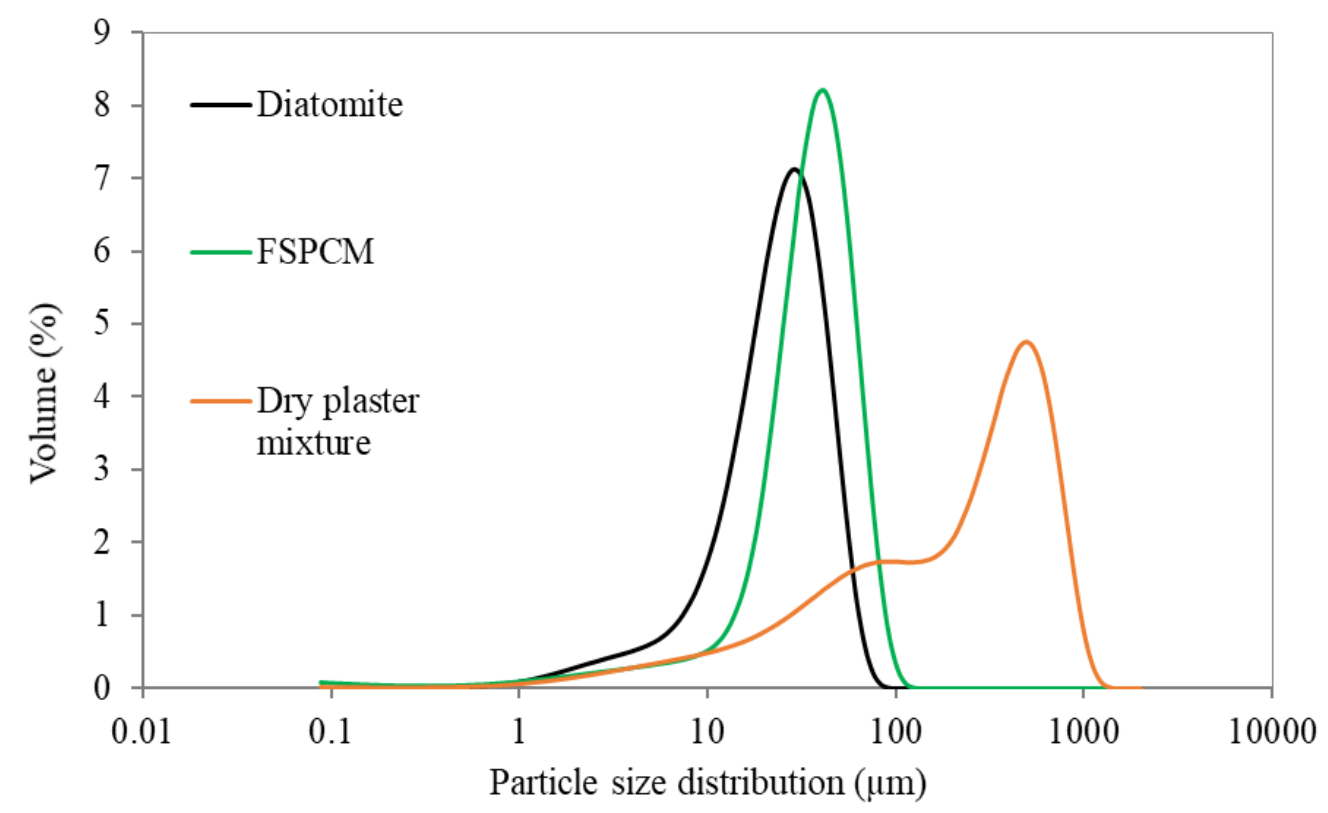

Figure 1. Particle size distribution.

Table 1. Composition of the studied plasters.

\begin{tabular}{ccccc}
\hline Mixture & Water & Dry Plaster & PCM & Flow Diameter \\
\cline { 2 - 5 } & $\mathbf{( k g )}$ & $\mathbf{( k g )}$ & $\mathbf{( k g )}$ & $\mathbf{( m m )}$ \\
\hline Reference plaster (RP) & 1.5 & 6.3 & 0 & 180 \\
Plaster with 8 wt.\% of FSPCM (P8) & 1.75 & 6.3 & 0.5 & 177 \\
Plaster with 16 wt.\% of FSPCM (P16) & 2.05 & 6.3 & 1 & 181 \\
Plaster with 24 wt.\% of FSPCM (P24) & 2.25 & 6.3 & 1.51 & 183 \\
\hline
\end{tabular}

\subsection{Determination Methods}

The basic physical properties of developed plasters were characterized by bulk density, matrix density, and total open porosity measurements. All these measurements were done on five cubic samples wide sides of about $50 \mathrm{~mm}$. The bulk density was determined based on the gravimetrical principle (using a digital caliper and weights). The matrix density was obtained by a Pycnomatic ATC helium pycnometer (Thermo Fisher Scientific, Waltham, Massachusetts, USA).

Determination of the pozzolanic activity was done by performing a Frattini test, specified by the European standard ČSN EN 196-5 [23]. The tested specimens were mixed with $100 \mathrm{~mL}$ of boiled distilled water. Afterward, samples were placed in a sealed plastic bottle and dried at $40{ }^{\circ} \mathrm{C}$ for 8 days and then were filtered with a Buchner funnel. The concentration of $\mathrm{OH}^{-}$ions was analyzed by titration against $\mathrm{HCl}$ with bromophenol blue indicator, and for $\mathrm{Ca}^{2+}$ concentration by $\mathrm{pH}$ adjustment to 12.5 by $\mathrm{NaOH}$, followed by titration with ethylenediaminetetraacetic acid (EDTA) solution using Murexide indicator [24].

Characterization of the inner structure of designed plasters was done by Mercury Intrusion Porosimetry (MIP) analysis. For this analysis, a combination of Pascal 140 and Pascal 440 porosimeters (Thermo Fisher Scientific, Waltham, Massachusetts, USA) was employed. The contact surface tension of mercury was $480 \mathrm{mN} / \mathrm{m}$ with the density of about $13,541 \mathrm{~g} / \mathrm{cm}^{3}$. The measurements were carried out at $21^{\circ} \mathrm{C}$.

Mechanical parameters such as the flexural strength and compressive strength were determined in order to access the durability of developed plasters. The measurement of compressive and flexural strengths was done by a VEB WPM Leipzig hydraulic testing device (WPM Leipzig, Leipzig, Germany) 
with a stiff loading frame with the capacity of $3000 \mathrm{kN}$ on prismatic samples with dimensions of $40 \mathrm{~mm} \times 40 \mathrm{~mm} \times 160 \mathrm{~mm}$.

The water vapor transmission properties of the developed plasters were measured using the cup method. Five samples with a circular cross-section of $110 \mathrm{~mm}$ diameter were used. The sample thickness was approx. $30 \mathrm{~mm}$. The measurements were carried under isothermal conditions at a temperature of $21^{\circ} \mathrm{C}$. The sealed cup was placed in a controlled climate chamber of approx. $50 \% \mathrm{RH}$ and weighed periodically. The steady-state values of mass gain or mass loss were utilized for the determination of the water vapor transfer properties [26].

For measurement of sorption and desorption isotherms, a dynamic DVS-Advantage vapor sorption device (Surface Measurement Systems, London, United Kingdom) was used. The measurements were done at $21^{\circ} \mathrm{C}$ for relative humidity levels of 20, 40, 60, 80 and 95\% RH. First, all tested samples were dried in an oven and put into a desiccator. Afterward, selected sample was placed in the climatic chamber of the DVS-Advantage device equipped by highly precise balances with resolution of $1.0 \mu \mathrm{g}$. A principle of the measurement is based on the gravimetric determination of mass gains and losses according to changes in relative humidity levels maintained by the device [26].

The thermal conductivity and thermal diffusivity were obtained by a hand-held portable instrument (ISOMET 2114, Applied Precision, Bratislava, Slovakia) based on a dynamic measurement principle which allow fast measurement with the accuracy of $5 \%$ of reading $+0.001 \mathrm{~W} /(\mathrm{mK})$. The reproducibility of measurements is $3 \%$ when reading in the temperature range from 0 to $40{ }^{\circ} \mathrm{C}$. Five cubic samples of about $70 \mathrm{~mm}$ side length were used and the obtained results were averaged.

For the measurement of phase change temperatures and enthalpies, differential scanning calorimetry (DSC) analysis was done. For this purpose, a DSC 822e apparatus (Mettler Toledo, Greifensee, Switzerland) equipped with a FT 900 cooling device (Julabo, Seelbach, Germany) was employed. During the measurements, the following temperature regimes were used: $5 \mathrm{~min}$ of isothermal regime, cooling at $0.5^{\circ} \mathrm{C} / \mathrm{min}$ from a temperature of $40{ }^{\circ} \mathrm{C}$ to a temperature of $0{ }^{\circ} \mathrm{C}, 5 \mathrm{~min}$ of isothermal regime, heating at $0.5^{\circ} \mathrm{C} / \mathrm{min}$ from $0{ }^{\circ} \mathrm{C}$ to $40^{\circ} \mathrm{C}, 5 \mathrm{~min}$ of isothermal regime. To obtain and present reliable results, DSC measurements were performed multiple-times $(5 \times)$ and consequently averaged. The long-term stability testing of the studied plasters was conducted by accelerated aging test and passing 100 cycles of the same heating/cooling rate and temperature range as described above.

\section{Results}

\subsection{Basic Physical Properties}

A material characterization of the plasters enriched by FSPCM according to their basic material properties is given in Table 2.

Table 2. Basic physical properties.

\begin{tabular}{cccc}
\hline Material & Bulk Density $\left(\mathbf{k g} / \mathbf{m}^{\mathbf{3}}\right)$ & Matrix Density $\left(\mathbf{k g} / \mathbf{m}^{\mathbf{3}}\right)$ & Total Open Porosity $(\mathbf{\%})$ \\
\hline RP & 1572 & 2415 & 34.9 \\
P8 & 1448 & 2294 & 37.8 \\
P16 & 1386 & 2179 & 35.3 \\
P24 & 1321 & 1982 & 35.6 \\
\hline
\end{tabular}

The obtained results revealed only minor changes in the material microstructure and a slight decrease in the bulk and matrix density was noted. As one can see, the average bulk density dropped from an initial value of $1572 \mathrm{~kg} / \mathrm{m}^{3}$ (RP) to $1321 \mathrm{~kg} / \mathrm{m}^{3}$ (P24) along with the matrix density. On the other hand, the total open porosity did not reveal a sharp dependency between the amount of used FSPCM and the pore volume. While P8 plaster exhibited an increase in the pore volume of about 3\%, applied higher dosages of FSPCM $(16 \%$ and $24 \%)$ reduced the total open porosity compared to P8 at almost the same level as was obtained for reference plaster. The explanation of this confusing fact can be 
found in the pore size distribution curves plotted in Figure 2. Here, a shift in macropore range revealed for P8 plaster can be associated with changes in the workability of fresh mixtures as well as different rheological properties. Concurrently, very fine FSPCM particles apparently filled large pores and promoted the increase of pores in the range from $0.01 \mu \mathrm{m}$ to $1 \mu \mathrm{m}$. As visible in Figure 2, plasters with higher dosages of FSPCM (P16 and P24) exhibit a lower threshold pore diameter compared to RP and P8 plaster. The achieved results pointed to a better incorporation of FSPCM compared to commercially produced inert PCMs [27], and according to the results revealed by Lee et al. [28] preservation of mechanical parameters can be expected.

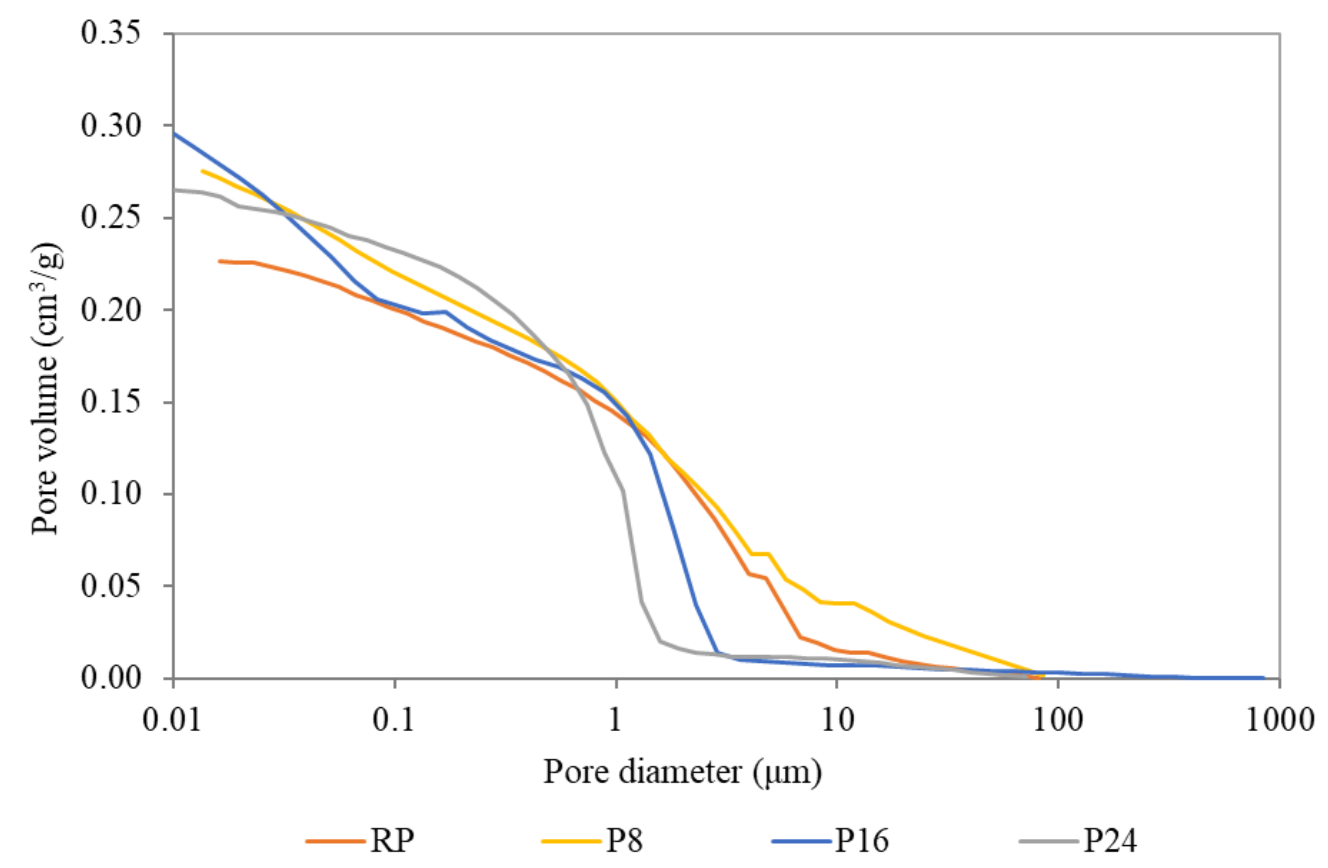

Figure 2. Pore diameter distribution of the studied plasters.

\subsection{Mechanical Properties}

One of the primary purposes related to the development of FSPCMs consists in the mitigation of the negative effects of commercially produced microencapsulated PCMs on the mechanical strength of designed composite materials, as described in several works $[12,13,20]$. The abrasion and possible damage of the polymer shells used during the mixing process represent important factors limiting a broader utilization of encapsulated PCMs in material design practice. Experimentally accessed results given in Table 3 show an effect of particular FSPCM dosages on the mechanical parameters of the tested plasters.

Table 3. Mechanical properties of studied plasters with FSPCM.

\begin{tabular}{cccc}
\hline Mixture & Compressive Strength (MPa) & Flexural Strength (MPa) & Young's Modulus (GPa) \\
\hline PR & 1.91 & 0.9 & 3.02 \\
P8 & 1.8 & 0.83 & 2.72 \\
P16 & 1.73 & 0.78 & 2.69 \\
P24 & 1.69 & 0.73 & 2.52 \\
\hline
\end{tabular}

All determined mechanical parameters (Young's modulus, compressive and flexural strength) for P24 dropped proportionally by approx. about $15 \%$ in comparison to RP. While the compressive strength was reduced from $1.91 \mathrm{MPa}$ to $1.69 \mathrm{MPa}$, the flexural strength decreased only by $0.17 \mathrm{MPa}$ to a final value of $0.73 \mathrm{MPa}$. Moreover, the P8 and P16 mixtures were affected in a lesser extent, thus the obtained results point to successful incorporation of FSPCM into cement-lime plaster matrix. The utilization 
of the newly developed FSPCM based on dodecanol and diatomite proved its contribution for the preservation of mechanical properties. Results obtained by Sun and Wang [29] for PCM composite based on paraffin and expanded perlite exhibited lower values, even when compared to P24 plaster with the highest FSCM dosage. They found that 30\% of incorporated paraffin/expanded perlite composite exhibited a decrease in compressive strength of more than about $25 \%$. This fact was caused by a high content of applied paraffin and limited reactivity of the shape stabilized composite with the cement during the hydration period.

\subsection{Thermal Properties and Energy Storage}

The thermal conductivity of plasters represents an important parameter for building designers, especially in the case of PCM composites. The results provided by Karkri et al. [30] highlighted that a lowered coefficient of thermal conductivity of the support material matrix is the limiting factor for PCM utilization in building practice.

Obtained thermal diffusivity and thermal conductivity results are presented in Table 4 to point out the changes induced by FSPCM admixture. As can be clearly seen, the coefficient of thermal conductivity was lowered very slightly, while only minor changes were also observed for the thermal diffusivity. This finding can be attributed to limited changes in material porosity and increased thermal conductivity of a pure FSPCM compared to commercial PCMs [31]. To be specific, almost insignificant changes in the tested thermal properties compared to the reference plaster were obtained, and the thermal conductivity values ranged between $0.52 \mathrm{~W} /(\mathrm{mK})$ and $0.54 \mathrm{~W} /(\mathrm{mK})$. The results achieved with our modified plasters are more favorable compared to the achievements discussed in the study of Kusama and Ishidoya [32], where a significant decrease in thermal conductivity was revealed for mixtures having a higher content of Micronal PCM.

Table 4. Thermal conductivity of studied plasters.

\begin{tabular}{ccc}
\hline Material & $\lambda(\mathbf{W} / \mathbf{m K})$ & $\boldsymbol{a}\left(\mathrm{m}^{2} / \mathbf{s}\right)$ \\
\hline RP & 0.54 & 0.36 \\
P8 & 0.52 & 0.33 \\
P16 & 0.53 & 0.34 \\
P24 & 0.53 & 0.34 \\
\hline
\end{tabular}

Contrary to the conventional building practice, the reduced thermal conductivity of PCM composites cannot be viewed as beneficial according to the conclusions of Joseph et al. [33] who stated a low thermal conductivity was a barrier for sufficient thermal energy transfer from the material to the environment. As reported by Ascione [34], the insufficient or very low thermal conductivity can be a reason for limited effectivity of applied PCMs or even restrict the occurrence of the phase change [32-34]. In the light of these findings, several studies suggested the application of expanded graphite in order to increase the thermal conductivity of PCMs $[17,18]$.

To investigate the influence of incorporated dodecanol/diatomite composite in cement-lime plaster, DSC analysis was employed for the identification of phase change intervals. The temperature dependent effective heat capacity curves obtained using a DSC device controlled by STAR SW 9.1 during the measurement of the studied modified plasters are shown in Figures 3 and 4 . Here, the phase change temperatures of the studied plasters were detected in the range of $21-19{ }^{\circ} \mathrm{C}$ during cooling, while the temperature ranged from $21{ }^{\circ} \mathrm{C}$ to $26{ }^{\circ} \mathrm{C}$ during the heating cycle. While the curve of temperature-dependent effective heat capacity during heating is more widespread, the crystallization during the cooling process exhibited a higher rate, therefore the onset and endset temperature differ only by about $2{ }^{\circ} \mathrm{C}$ at maximum. Detailed information about the onset and endset temperatures, together with the heats of phase change is given in Table 5 . 


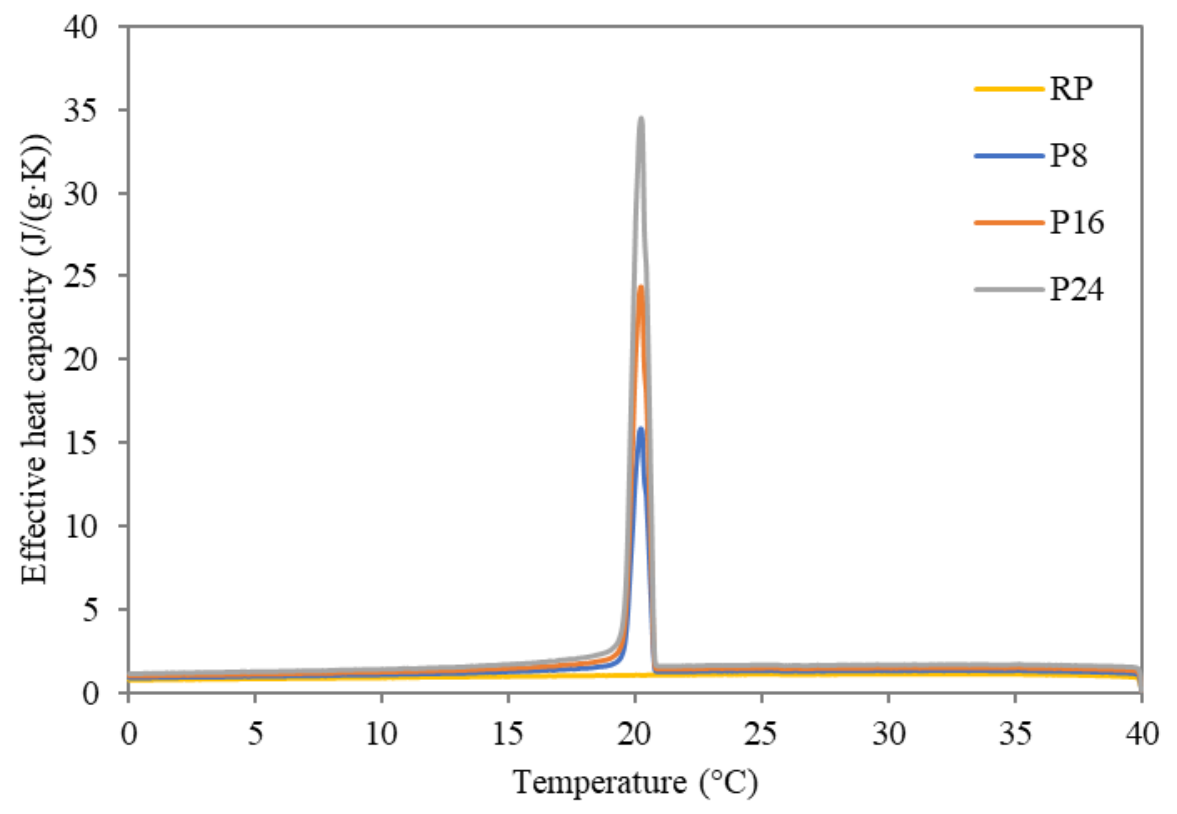

Figure 3. Temperature dependent effective heat capacity of studied FSPCM plasters during cooling.

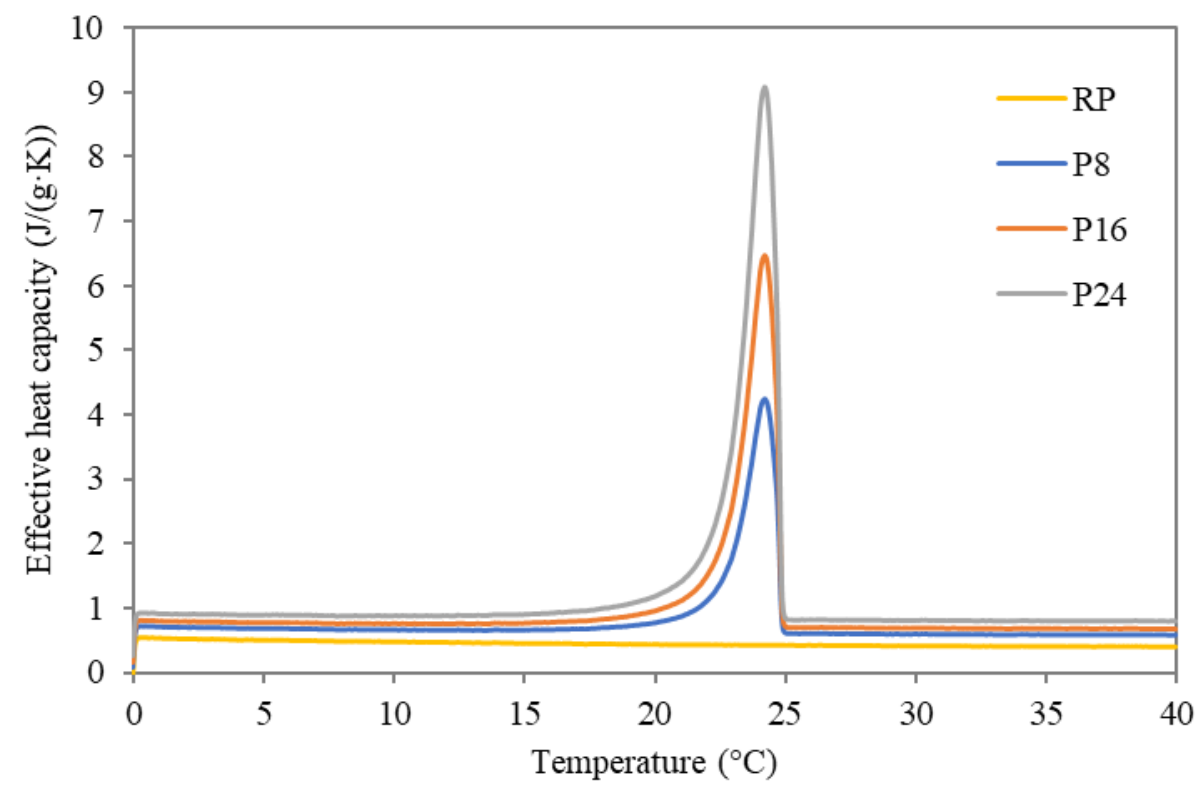

Figure 4. Temperature dependent effective heat capacity of studied FSPCM plasters during heating.

Table 5. Phase change temperatures of studied plasters and specific enthalpies.

\begin{tabular}{ccccccc}
\hline \multirow{2}{*}{ Material } & \multicolumn{3}{c}{ Phase Change Temperature $\left({ }^{\circ} \mathbf{C}\right)$} & \multicolumn{2}{c}{ Phase Change Enthalpy (J/g) } \\
\cline { 2 - 5 } & \multicolumn{2}{c}{ Heating } & \multicolumn{2}{c}{ Cooling } & \multirow{2}{*}{ Heating } & Cooling \\
\cline { 2 - 5 } & Onset & Endset & Onset & Endset & & \\
RP & - & - & - & - & - & - \\
P8 & 21.46 & 24.68 & 20.68 & 18.63 & 4.63 & 4.89 \\
P16 & 21.13 & 24.91 & 20.81 & 18.98 & 10.11 & 10.28 \\
P24 & 21.68 & 25.86 & 20.75 & 19.66 & 15.20 & 15.38 \\
\hline
\end{tabular}

Looking at the data, the incorporation of FSPCM into the plaster matrix did not dramatically affect the onset nor endset temperatures compared to data for pure FSPCM. Only a slight spread of the phase change interval was observed, which cannot be perceived as a barrier for material utilization. 
Specifically, all measured phase change temperature intervals remained in the desired range suitable for the moderation of the indoor climate. The latent heat of prepared plasters was increased proportionally to applied FSPCM dosages, thus providing thermal storage capacity improvements compared to the reference plaster. The obtained heat flux curves kept their unimodal shape, which provides substantial benefits compared to composites based on commercial PCMs. Reported bimodal heat flux curves pointed out a reduced ability of applied PCMs to maintain the indoor temperature in the desired range due to incomplete phase changes [35]. Considering the relatively narrow operational range (desired from $20{ }^{\circ} \mathrm{C}$ to $24{ }^{\circ} \mathrm{C}$ ) of the PCMs used, unimodal shape of the temperature-dependent apparent heat capacity allows maximization of the heat absorption/release effectivity. In other words, such a material ensures operation in the desired range with improved effectivity compared to bimodal shape curves with usually more widespread operational ranges. The achieved results inevitably exhibited a strong dependence between the values of latent heat and applied FSPCM dosages. P8 plaster revealed the ability to absorb about $4.63 \mathrm{~J} / \mathrm{g}$ during the heating cycle and release of about $4.89 \mathrm{~J} / \mathrm{g}$ during the cooling cycle. On the contrary, the plaster with the highest FSPCM dosage showed better results, namely a phase change enthalpy of about $15.20 \mathrm{~J} / \mathrm{g}$ during heating and $15.38 \mathrm{~J} / \mathrm{g}$ during the cooling cycle. Considering the results revealed in similar studies, the developed plaster with FSPCM exhibited a notable improvement compared to similar products. Namely, in the work of $\mathrm{Xu}$ and $\mathrm{Li}$ [36] about three times lower values (ranging from $1.32 \mathrm{~J} / \mathrm{g}$ to $5.44 \mathrm{~J} / \mathrm{g}$ ) in cement composite enriched by paraffin-based form-stable PCM were recorded. The attempt of Liu et al. [37] to develop calcium silicate-coated expanded clay-based form stable PCM for application in cement composite delivered a substantial improvement (about $58 \%$ increase in effective heat capacity compared to reference sample). Nonetheless, the latent heat varied from $1.54 \mathrm{~J} / \mathrm{g}$ to $2.8 \mathrm{~J} / \mathrm{g}$ only. From this point of view, the developed composite plasters provide substantially improved thermal storage properties in the desired temperature range.

\subsection{Long-Term Stability of FSPCM Plaster Thermal Storage Properties}

The long-term stability of FSPCM poses another critical parameter for assessment of thermal energy storage composites. In order to determine this parameter, P24 plaster with the highest content of FSPCM (highest probability of leakage) was studied by DSC analysis intermediately after fabrication and after completing 100 cycles (see Figure 5).

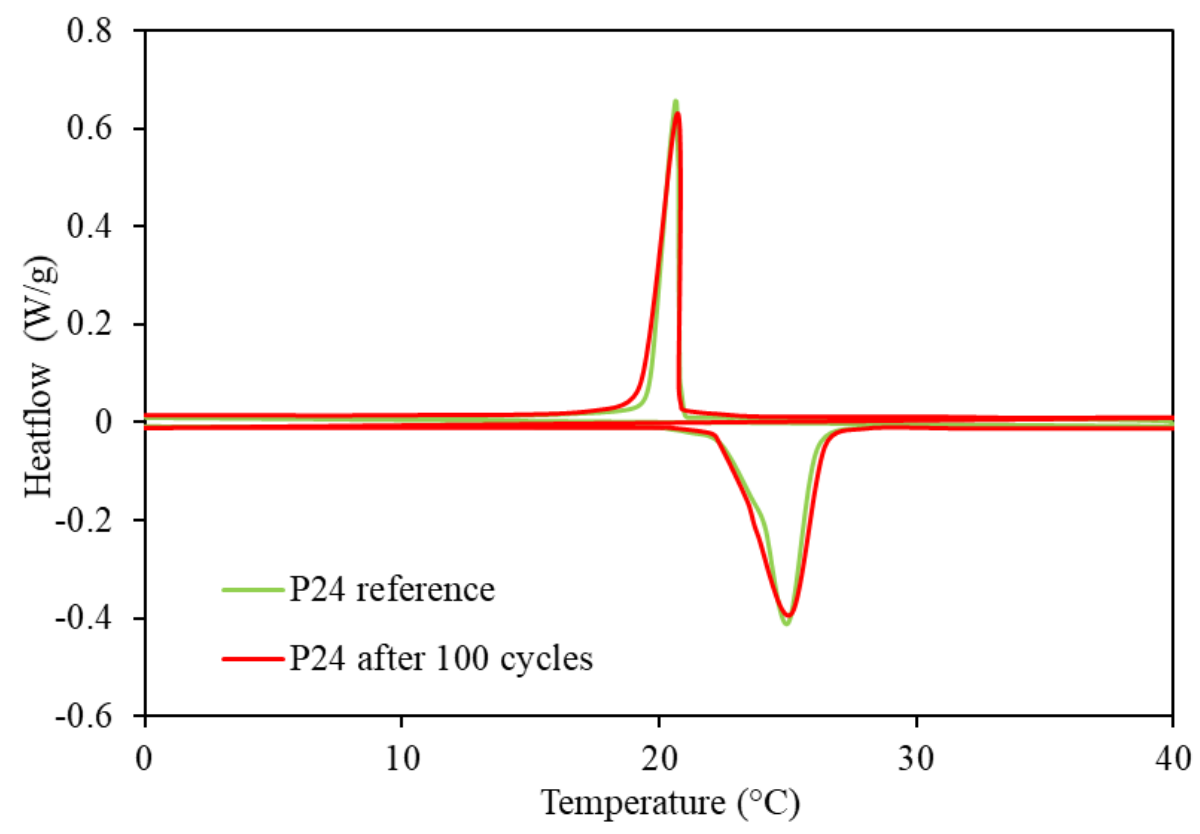

Figure 5. Long-term stability of developed plaster-mixture P24 after 100 cycles. 
Looking at the plotted curves, the onset and endset temperatures did not display any distinct shift or drop. The onset phase change temperature during cooling was moved slightly from $20.69^{\circ} \mathrm{C}$ to $20.75^{\circ} \mathrm{C}$ and from $21.53^{\circ} \mathrm{C}$ to $21.68{ }^{\circ} \mathrm{C}$ during heating. The latent heat of fusion decreased from 15.78 to $15.20 \mathrm{~J} / \mathrm{g}$, and the latent heat of freezing was reduced from $15.89 \mathrm{~J} / \mathrm{g}$ to $15.38 \mathrm{~J} / \mathrm{g}$. Therefore, this minor drop clearly depicted the long-term stability and no leakage was observed. As described by Feczko et al. [35], the leakage is usually recognized within the first cycles and decrease in time (higher number of cycles). Taking into account these results, the FSPCM plasters based on dodecanol and diatomite remain stable even after 100 thermal cycles and can be expected to preserve this stability even after a higher number of cycles.

\subsection{Hygric Properties}

The water vapor resistance factors determined by the cup method, together with the moisture conductivity of studied FSPCM plasters are given in Table 6.

Table 6. Hygric properties of the studied plasters.

\begin{tabular}{ccc}
\hline Material & $\kappa\left(\mathrm{m}^{2} / \mathbf{s}\right)$ & $\mu(-)$ \\
\hline RP & $5.66 \times 10^{-7}$ & 9.4 \\
P8 & $5.87 \times 10^{-7}$ & 8.9 \\
P16 & $6.23 \times 10^{-7}$ & 8.5 \\
P24 & $6.80 \times 10^{-7}$ & 8.3 \\
\hline
\end{tabular}

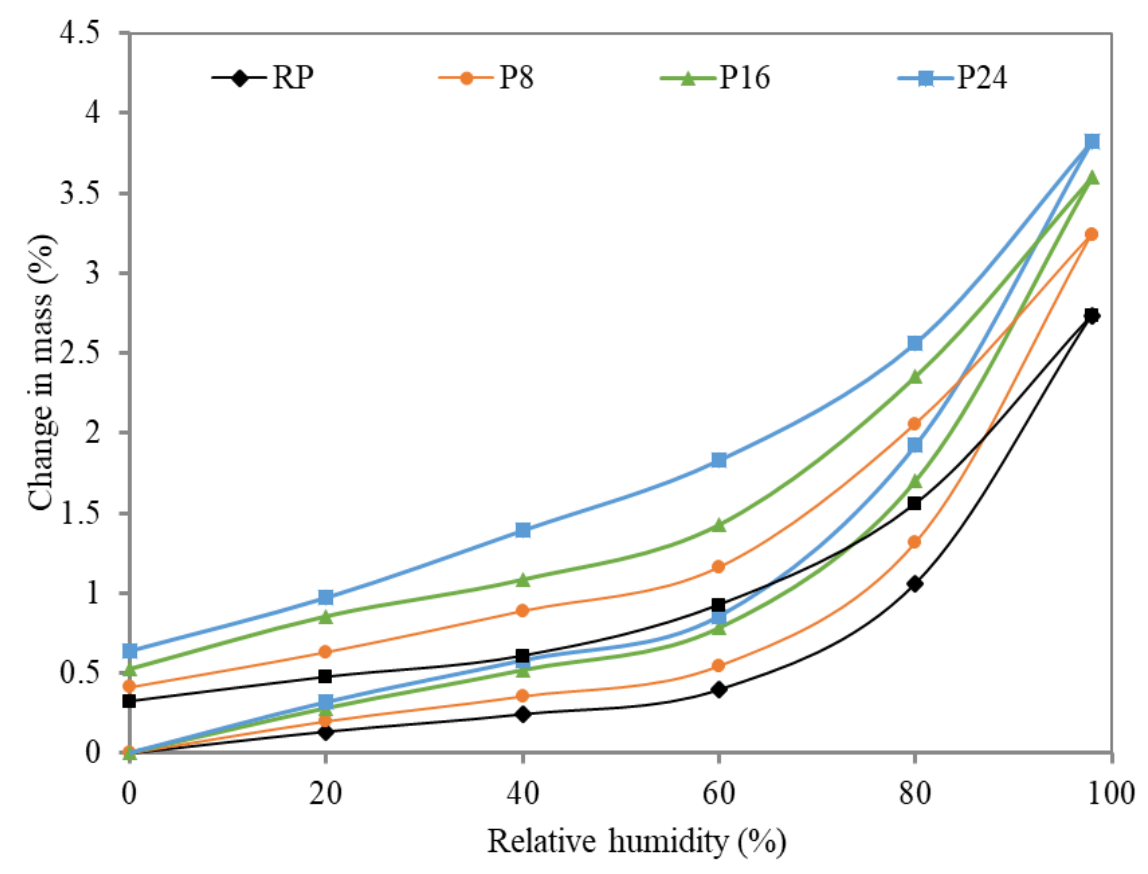

Figure 6. Sorption and desorption isotherms.

These parameters describe the water transport predominantly from the exterior side to the interior and vice versa, which substantially affects the thermal conductivity. As is clearly visible, the obtained experimental results did not indicate any substantial differences between reference samples and modified plasters. While the water vapor resistance factor for RP reached 9.4, the applied FSPCM moved this value for P8, P16, and P24 to 8.9, 8.5 and 8.3, respectively. The calculated parameters exhibited only a slight decrease in the water vapor resistivity which can be partially assigned to changes in the porous space, the formation of pores with smaller diameter compared to reference plaster and on the other hand to the improved hygroscopicity. This effect is evident from Figure 6, where the sorption and desorption isotherms are plotted. Here, studied samples were exposed to various levels of relative 
humidity ranging from 0 to approx. $95 \%$ at a constant temperature $\left(21^{\circ} \mathrm{C}\right)$ to reveal the relationship between sample mass and the applied relative humidity level.

The equilibrium moisture content (EMC) can also be used for interpretation of material ability to moderate indoor humidity during the diurnal swings. The record of this measurement complies with previously described results of water vapor transmission properties. The EMC of RP, P8, P16, and P24 was measured to be 2.74, 3.24, 3.60 and 3.83\%, respectively. Obtained results of modified plasters represent a distinct shift in the measured parameter, which can be beneficially utilized for control of indoor humidity levels in terms of moisture buffering [38].

\section{Conclusions}

This study focused on the design of new thermal energy storage plasters provided detailed information about the basic physical, thermal, mechanical, and hygric properties of modified plasters enhanced by 8,16 , and 24 wt.\% of FSPCM based on diatomite and dodecanol. The obtained results represent important data for the applicability of the studied materials as well as moderation of the indoor climate with respect to the diurnal or seasonal temperature fluctuations or changes. The following points should be highlighted:

- A substantial improvement was achieved in the field of preservation of functional parameters, where only slight deterioration was found. Namely, a decrease of about only $13 \%$ for the compressive and flexural strengths was observed compared to reference plaster in the case of a $24 \mathrm{wt.} \%$ FSPCM admixture. This finding showed that diatomite particles could be utilized as suitable bearer material for PCMs due to their compatibility with cementitious materials. Moreover, the developed FSPCM exhibited improved mechanical performance compared to commercially produced PCMs.

- Thermal conductivity of the developed plasters was decreased only slightly, therefore the capability to release and absorb thermal energy was influenced only slightly.

- Hygric parameters of the modified plaster were slightly improved thanks to an increase in the total open porosity, thus the material provides a better moisture-moderation capability compared to reference plaster.

- The incorporation of FSPCM into the cement-lime plaster did not shift the phase change temperature, which remained stable for all tested mixtures. On the other hand, the phase change enthalpy was proportionally decreased depending on the volume of the applied PCM. The phase change temperatures varied from $21.68^{\circ} \mathrm{C}$ during heating to $20.75{ }^{\circ} \mathrm{C}$ during cooling for plaster with $24 \mathrm{wt} . \%$ of FSPCM, while the phase change enthalpy reached values of about $15.38 \mathrm{~J} / \mathrm{g}$ during cooling, and $15.20 \mathrm{~J} / \mathrm{g}$ during heating, respectively. The obtained values remained stable even after 100 heating-cooling cycles, therefore, no leakage was detected.

Considering the results of this study, further experimental tests for verification of the positive effect of the form-stable PCM composite should be performed. Here, semi-scale and full-scale experiments in particular could be helpful in order to prove the assumed energy savings in building maintenance.

Author Contributions: Conceptualization, J.F. and R.Č.; methodology, J.F: and A.T.; validation, R.N. and A.T.; formal analysis, R.Č.; investigation, J.F., R.N. and A.T.; resources, R.N and R.Č.; data curation, J.F and A.T.; writing—original draft preparation, J.F.; writing—review and editing, J.F.; visualization, J.F.; supervision, R.Č.; project administration, J.F.; funding acquisition, J.F. and R.N.

Funding: This research has been supported by the Czech Science Foundation, under project No 18-03997S and specific university research of the Institute of Technology and Business in České Budějovice, under project No SVV201906.

Conflicts of Interest: The authors declare no conflict of interest. 


\section{References}

1. Samuel, D.G.L.; Nagendra, S.M.S.; Maiya, M.P. Passive alternatives to mechanical air conditioning of building: A review. Build. Environ. 2013, 66, 54-64. [CrossRef]

2. Allwood, J.M.; Cullen, J.M.; Milford, R.L. Options for Achieving a 50\% Cut in Industrial Carbon Emissions by 2050. Environ. Sci. Technol. 2010, 44, 1888-1894. [CrossRef] [PubMed]

3. Jelle, B.P. Traditional, state-of-the-art and future thermal building insulation materials and solutionsProperties, requirements and possibilities. Energy Build. 2011, 43, 2549-2563. [CrossRef]

4. Alam, M.; Singh, H.; Suresh, S.; Redpath, D.A.G. Energy and economic analysis of Vacuum Insulation Panels (VIPs) used in non-domestic buildings. Appl. Energy 2017, 188, 1-8. [CrossRef]

5. Hill, C.; Norton, A.; Dibdiakova, J. A comparison of the environmental impacts of different categories of insulation materials. Energy Build. 2018, 162, 12-20. [CrossRef]

6. Pombo, O.; Allacker, K.; Rivela, B.; Neila, J. Sustainability assessment of energy saving measures: A multi-criteria approach for residential buildings retrofitting-A case study of the Spanish housing stock. Energy Build. 2016, 116, 384-394. [CrossRef]

7. Koci, J.; Koci, V.; Madera, J.; Cerny, R. Effect of applied weather data sets in simulation of building energy demands: Comparison of design years with recent weather data. Renew. Sustain. Energy Rev. 2019, 100, 22-32. [CrossRef]

8. Alva, G.; Lin, Y.X.; Liu, L.K.; Fang, G.Y. Synthesis, characterization and applications of microencapsulated phase change materials in thermal energy storage: A review. Energy Build. 2017, 144, 276-294. [CrossRef]

9. Bruno, F.; Tay, N.H.S.; Belusko, M. Minimising energy usage for domestic cooling with off-peak PCM storage. Energy Build. 2014, 76, 347-353. [CrossRef]

10. Park, J.H.; Jeon, J.; Lee, J.; Wi, S.; Yun, B.Y.; Kim, S. Comparative analysis of the PCM application according to the building type as retrofit system. Build. Environ. 2019, 151, 291-302. [CrossRef]

11. Ramakrishnan, S.; Wang, X.M.; Sanjayan, J.; Petinakis, E.; Wilson, J. Development of thermal energy storage cementitious composites (TESC) containing a novel paraffin/hydrophobic expanded perlite composite phase change material. Sol. Energy 2017, 158, 626-635. [CrossRef]

12. Biswas, K.; Lu, J.; Soroushian, P.; Shrestha, S. Combined experimental and numerical evaluation of a prototype nano-PCM enhanced wallboard. Appl. Energy 2014, 131, 517-529. [CrossRef]

13. Figueiredo, A.; Lapa, J.; Vicente, R.; Cardoso, C. Mechanical and thermal characterization of concrete with incorporation of microencapsulated PCM for applications in thermally activated slabs. Constr. Build. Mater. 2016, 112, 639-647. [CrossRef]

14. Entrop, A.G.; Brouwers, H.J.H.; Reinders, A. Experimental research on the use of micro-encapsulated Phase Change Materials to store solar energy in concrete floors and to save energy in Dutch houses. Sol. Energy 2011, 85, 1007-1020. [CrossRef]

15. Hunger, M.; Entrop, A.G.; Mandilaras, I.; Brouwers, H.J.H.; Founti, M. The behavior of self-compacting concrete containing micro-encapsulated Phase Change Materials. Cem. Concr. Compos. 2009, 31, 731-743. [CrossRef]

16. Costanzo, V.; Evola, G.; Marletta, L.; Nocera, F. The effectiveness of phase change materials in relation to summer thermal comfort in air-conditioned office buildings. Build. Simul. 2018, 11, 1145-1161. [CrossRef]

17. Zhang, Z.G.; Shi, G.Q.; Wang, S.P.; Fang, X.M.; Liu, X.H. Thermal energy storage cement mortar containing n-octadecane/expanded graphite composite phase change material. Renew. Energy 2013, 50, 670-675. [CrossRef]

18. Sari, A.; Karaipekli, A. Preparation, thermal properties and thermal reliability of palmitic acid/expanded graphite composite as form-stable PCM for thermal energy storage. Sol. Energy Mater. Sol. Cells 2009, 93, 571-576. [CrossRef]

19. He, Y.; Zhang, X.; Zhang, Y.J. Preparation technology of phase change perlite and performance research of phase change and temperature control mortar. Energy Build. 2014, 85, 506-514. [CrossRef]

20. Schossig, P.; Henning, H.M.; Gschwander, S.; Haussmann, T. Micro-encapsulated phase-change materials integrated into construction materials. Sol. Energy Mater. Sol. Cells 2005, 89, 297-306. [CrossRef]

21. Figueiredo, A.; Vicente, R.; Lapa, J.; Cardoso, C.; Rodrigues, F.; Kampf, J. Indoor thermal comfort assessment using different constructive solutions incorporating PCM. Appl. Energy 2017, 208, 1208-1221. [CrossRef]

22. Fort, J.; Trnik, A.; Pavlikova, M.; Pavlik, Z.; Cerny, R. Fabrication of Dodecanol/Diatomite Shape-Stabilized PCM and Its Utilization in Interior Plaster. Int. J. Thermophys. 2018, 39, 11. [CrossRef] 
23. Czech Standardization Institute. Methods of Cement Testing-Part 5: Pozzolanicity Testing, ČSN EN 196-5; Czech Standardization Institute: Prague, Czech Republic, 2011.

24. Fort, J.; Pavlikova, M.; Zaleska, M.; Pavlik, Z.; Trnik, A.; Jankovsky, O. Preparation of puzzolana active two component composite for latent heat storage. Ceram. Silik. 2016, 60, 291-298. [CrossRef]

25. British Standards Institution. Particle Characterization, ISO 13320. ISO/TC24/SC4/WG6. British Standards Institution: London, UK, 1981.

26. Fort, J.; Pavlik, Z.; Zumar, J.; Pavlikova, M.; Cerny, R. Effect of temperature on water vapor transport properties. J. Build. Phys. 2014, 38, 156-169. [CrossRef]

27. Souayfane, F.; Fardoun, F.; Biwole, P.H. Phase change materials (PCM) for cooling applications in buildings: A review. Energy Build. 2016, 129, 396-431. [CrossRef]

28. Lee, K.O.; Medina, M.A.; Sun, X.Q.; Jin, X. Thermal performance of phase change materials (PCM)-enhanced cellulose insulation in passive solar residential building walls. Sol. Energy 2018, 163, 113-121. [CrossRef]

29. Sun, D.; Wang, L.J. Utilization of paraffin/expanded perlite materials to improve mechanical and thermal properties of cement mortar. Constr. Build. Mater. 2015, 101, 791-796. [CrossRef]

30. Karkri, M.; Lachheb, M.; Nogellova, Z.; Boh, B.; Sumiga, B.; AlMaadeed, M.A.; Fethi, A.; Krupa, I. Thermal properties of phase-change materials based on high-density polyethylene filled with micro-encapsulated paraffin wax for thermal energy storage. Energy Build. 2015, 88, 144-152. [CrossRef]

31. Pavlik, Z.; Fort, J.; Pavlikova, M.; Pokorny, J.; Trnik, A.; Cerny, R. Modified lime-cement plasters with enhanced thermal and hygric storage capacity for moderation of interior climate. Energy Build. 2016, 126, 113-127. [CrossRef]

32. Kusama, Y.; Ishidoya, Y. Thermal effects of a novel phase change material (PCM) plaster under different insulation and heating scenarios. Energy Build. 2017, 141, 226-237. [CrossRef]

33. Joseph, A.; Kabbara, M.; Groulx, D.; Allred, P.; White, M.A. Characterization and real-time testing of phase-change materials for solar thermal energy storage. Int. J. Energy Res. 2016, 40, 61-70. [CrossRef]

34. Ascione, F. Energy conservation and renewable technologies for buildings to face the impact of the climate change and minimize the use of cooling. Sol. Energy 2017, 154, 34-100. [CrossRef]

35. Feczko, T.; Trif, L.; Horak, D. Latent heat storage by silica-coated polymer beads containing organic phase change materials. Sol. Energy 2016, 132, 405-414. [CrossRef]

36. Xu, B.W.; Li, Z.J. Paraffin/diatomite composite phase change material incorporated cement-based composite for thermal energy storage. Appl. Energy 2013, 105, 229-237. [CrossRef]

37. Liu, Y.S.; Xie, M.J.; Xu, E.T.; Gao, X.; Yang, Y.Z.; Deng, H.W. Development of calcium silicate-coated expanded clay based form-stable phase change materials for enhancing thermal and mechanical properties of cement-based composite. Sol. Energy 2018, 174, 24-34. [CrossRef]

38. Wu, Z.M.; Qin, M.H.; Zhang, M.J. Phase change change humidity control material and its impact on building energy consumption. Energy Build. 2018, 174, 254-261. [CrossRef] 